\title{
Potential of activated carbon to recover randomly-methylated- $\beta$-cyclodextrin solution from washing water originating from in situ soil flushing
}

\author{
K. Sniegowski ${ }^{\text {a } *}$, M. Vanhecke ${ }^{\text {b }}$, P.-J. D'Huys ${ }^{\text {b }}$, L. Braeken ${ }^{\text {a }}$ \\ a Researchgroup Lab4U, Faculty of Industrial Engineering, Katholieke Universiteit Leuven (KU Leuven - Diepenbeek), Agoralaan gebouw B, bus 8, Diepenbeek, Belgium \\ b Researchgroup Lab4U, Department of Industrial Science and Technology, Catholic University College Limburg, Agoralaan gebouw B, bus 3, Diepenbeek, Belgium
}

\section{H I G H L I G H T S}

- RAMEB significantly accelerates the treatment of a diesel contaminated soil.

- $>90 \%$ of the mineral oil from the washing water is removed by activated carbon.

- $100 \%$ of the cyclodextrin solution can be reused for reinfiltration.

- Reusing cyclodextrin washing solution makes the technique more economical feasible.

\section{A R T I C L E I N F O}

\section{Article history:}

Received 29 June 2013

Received in revised form 12 November 2013

Accepted 23 November 2013

Available online $\mathrm{xxxx}$

\section{Keywords:}

Cyclodextrin

Mineral oil

Activated carbon

Soil aquifer remediation

In-situ soil flushing

\begin{abstract}
A B S T R A C T
Despite the overall high efficacy of cyclodextrins to accelerate the treatment of soil aquifer remediation by in-situ soil flushing, the use in practice remains limited because of the high costs of cyclodextrin and high concentrations needed to significantly reduce the treatment time. The current study tested the potential of activated carbon to treat washing water originating from soil flushing in order to selectively separate hydrocarbon contaminants from washing water containing cyclodextrin and subsequently reuse the cyclodextrin solution for reinfiltration. A high recovery of the cyclodextrin from the washing water would reduce the costs and would make the technique economically feasible for soil remediation. This study aimed to investigate whether cyclodextrin can pass through the activated carbon filter without reducing the cyclodextrin concentration when the contaminated washing water is treated and whether the presence of cyclodextrin negatively affects the purification potential of activated carbon to remove the organic pollutants from the pumped soil water. Lab-scale column experiments showed that with the appropriate activated carbon $100 \%$ of cyclodextrin (randomly-methylated- $\beta$-cyclodextrin) can be recovered from the washing water and that the effect on the efficiency of activated carbon to remove the hydrocarbon contaminants remains limited. These results show that additional field tests are useful to make insitu soil flushing with cyclodextrin both a technical and an economical interesting technique. These results might stimulate the application of cyclodextrin in soil treatment technology.
\end{abstract}

(c) 2013 Elsevier B.V. All rights reserved.

\section{Introduction}

Soil flushing with solubilizing agents is an interesting alternative for the frequently used pump and treat method to remediate soil aquifers. Because of their low toxicity and biodegradability, the use of biobased solubility enhancers, such as biosurfactants, is preferred over chemical additives such as cosolvent (Kosaric, 2001) and surfactants (Svab et al., 2009; Zhou and Zhu, 2008). A disadvantage of biosurfactants is however that their hydrophobic part adsorbs to the soil. This makes them less efficient in interacting with hydrophobic compounds and

\footnotetext{
* Corresponding author.

E-mail address: kristel.sniegowski@kuleuven.be (K. Sniegowski).

URL: http://www.khlim.be/lab4U (K. Sniegowski).
}

more difficult to recover from the soil for reuse. More suitable biobased solubilizing agents for soil remediation are cyclodextrins (CD). CD are $(\alpha-1,4)$-linked oligosaccharides with both an apolar cavity and polar exterior and are able to encapsulate hydrophobic contaminants (Fig. 1), thereby enhancing their solubility and accelerating the soil flushing process (Berselli et al., 2006). In addition, by enhancing the water solubility, apolar contaminants become more bioavailable, accelerating the bioremediation process (Gan et al., 2009; McCray et al., 2000). Because of their cyclic structure $C D$, in contrast to biosurfactants, adsorb very little to the soil surface (Brusseau et al., 1994; Zeng et al., 2006), which makes it more easy to reuse cyclodextrin solutions. In addition, they don't increase the hydrophobicity of the soil surface thereby decreasing the solubilization of the contaminants (Fenyvesi et al., 2009). 

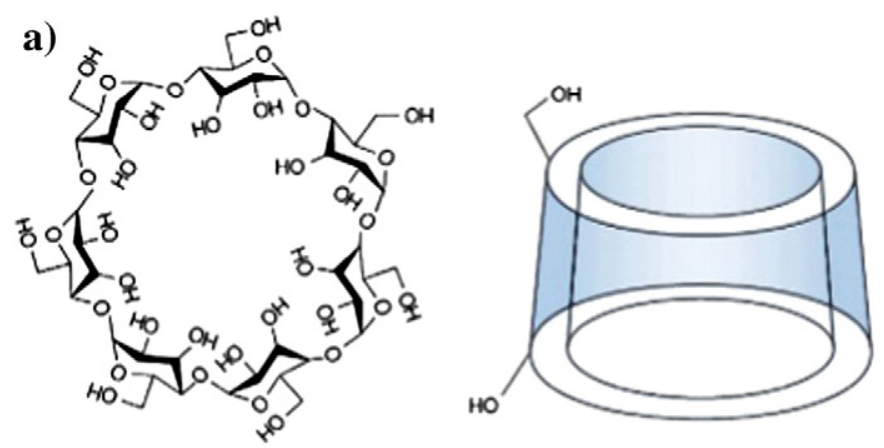

b)

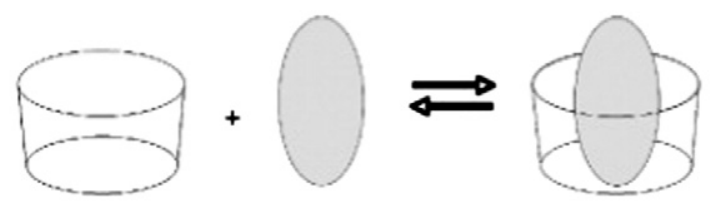

Fig. 1. Schematic view of (a) the structure of cyclodextrin and (b) mechanism of inclusion formation with a molecule (adapted from Davis and Brewster, 2004).

Research has been published regarding the enhancement of the water solubility and/or bioavailability of contaminants with $\mathrm{CD}$ for a wide range of contaminants such as PCB (Balogh et al., 2007), trichloroethene (Fenyvesi et al., 2010), polycyclic aromatic hydrocarbons (Viglianti et al., 2006; Wang et al., 2005) and pesticides (Morillo et al., 2001; Wong and Bidleman, 2010). In addition, some field trials to test the remediation of chlorinated solvent-contaminated aquifer with cyclodextrin obtained good results (Blanford et al., 2001; Boving et al., 1998; McCray and Brusseau, 1998; Tick et al., 2003).

Despite the overall high observed efficacy, for now the practical use is limited because of the high costs of $C D$ and high concentrations needed to reduce the treatment time significantly. Cyclodextrin concentrations used to achieve a significant improved desorption in field trials are situated between $1.5 \%(\mathrm{w} / \mathrm{v})$ and $20 \%$ resulting in contaminant concentrations between 3 and 20,000 times higher than during a water flush (w/v) (Blanford et al., 2001; Boving et al., 1998; McCray and Brusseau, 1998; Leitgib et al., 2008; Tick et al., 2003). A high recovery of the $\mathrm{CD}$ from the washing would reduce the costs and makes the technique also economically interesting for the soil remediation industry. Boving et al. (1998) already emphasized the importance of reusing cyclodextrin to make soil flushing viable. For the volatile contaminants such as tetrachloroethene and trichloroethene they tested the removal of the contaminants from cyclodextrin containing water by air stripping. Alternative methods are required for less volatile contaminants. This study proposes the use of activated carbon (AC) to treat washing water from soil flushing with cyclodextrin to selectively separate hydrocarbon contaminants from the washing water containing cyclodextrins. Therefore, a type of AC with minimal sorption capacity for cyclodextrins is needed. Until now, only Kania et al. (2012) looked into the adsorption of cyclodextrin to AC and were able to establish adsorption isotherms. They found that especially cyclodextrins with methyl or alkylammonium groups are able to incorporate in the carbon framework (Kania et al., 2012). However, due to the limited amount of publications regarding this topic additional research regarding the possibilities of reusing cyclodextrin by AC is essential.

In addition, it is necessary to ensure that the contaminantcyclodextrin complex stability is not too high since it might either reduce the efficiency of AC to remove the organic contaminants from the washing water or lower the recovery of the cyclodextrin molecules since the contaminant-cyclodextrin complex might adsorb to the AC. Recent studies rather looked into the potential of cyclodextrin to remove the adsorbed contaminants to regenerate AC. For example, Morley et al. (2006) used different solubility enhancing agents such as cyclodextrins to remove the cyclotrimethylenetrinitramine or the explosive RDX sorbed on granular AC for its regeneration. However, since it is necessary to clean the water prior to reuse or discharge, more studies are necessary to ensure that cyclodextrin-hydrophobic contaminant inclusion complexes do not jeopardize the cleaning efficiency of AC. This study will look into both issues using randomlymethylated- $\beta$-cyclodextrin (RAMEB) as cyclodextrin. This type of cyclodextrin contains seven $\alpha$-D glucopyranose units which are methylated on the outer hydroxyl groups with a substitution rate of 1.7-1.8. Earlier studies of different authors (including our own bioremediation studies) designate RAMEB as a potential in-field solubiliser because of its high half-life time (1 to 2 years, Fenyvesi et al., 2005) and relative low cost (Fava and Ciccotosto, 2002). In addition, many good results have been obtained with RAMEB to enhance the bioavailability or bioremediation of soils contaminated with hydrocarbons (Molnár et al., 2002, 2005).

The present study aims to investigate whether or not RAMEB can be recovered from contaminated washing water when it is treated with $A C$ and whether RAMEB negatively affects the purification step to remove the organic pollutants with AC. More specifically, this paper investigates (i) how much RAMEB is lost by sorption to AC and which type of AC results in the minimal loss of RAMEB, (ii) whether the RAMEB concentration in the water affects the sorption of $C D$ to $A C$, (iii) whether the presence of dissolved organic carbon in the flushing water affects the retention of cyclodextrin and finally (iv) the efficiency of AC to remove mineral oil from the flushing water in the presence of RAMEB. This paper will contribute to the applicability of RAMEB in the field.

\section{Materials and methods}

\subsection{Batch adsorption experiments}

Four types of AC's from Desotec, were used for the batch adsorption experiments. Granulated AC (mesh size $8 * 30$ ), i.e., AC-A and AC-D were made from stone coal, while $A C-B$ and $A C-C$ were made from coconut shells. All types of $A C$ are used in water treatment to remove organic contaminants. Randomly-methylated- $\beta$-cyclodextrin (RAMEB), product name Cavasoil ${ }^{\circ}$ W7 M, was obtained from Wacker Biosolutions (Germany).

In the first batch experiment, adsorption experiments were performed in $250 \mathrm{~mL}$ flasks containing $10 \mathrm{~g} / \mathrm{L}$ RAMEB in $100 \mathrm{~mL}$ tap water. The four types of granular AC were grinded to powder and particles smaller than $63 \mu \mathrm{m}$ were added to the solution. The appropriate AC was added to the solution to achieve the concentrations $0,0.1,1.0,5.0$ or $10 \mathrm{~g} \mathrm{AC} \mathrm{L}^{-1}$. Each test was performed in duplicate. After $4 \mathrm{~h}$ on a magnetic stir plate, the water was filtrated over a $0.45 \mu \mathrm{m}$ filter. Preliminary tests with blancs containing no AC showed that the filter needs to be rinsed in order to remove the excess of unbound RAMEB. Therefore the $\mathrm{AC}$ on the filter was washed after filtration with $100 \mathrm{~mL}$ of clean water. The concentration of RAMEB in the water was measured in $1 \mathrm{~mL}$ of sample using HPLC-ELSD.

A second batch experiment with AC-B and AC-C was performed to test whether the adsorption of RAMEB depends on the concentration of RAMEB in the solution. Powdered granular AC ( $10 \mathrm{~g} / \mathrm{L})$ was pretreated as described before and added to tap water containing RAMEB of $0,5,10$, 20 or $50 \mathrm{~g} / \mathrm{L}$. Each test was performed in duplicate. After $4 \mathrm{~h}$ on a magnetic stir plate, the water was filtrated over $0.45 \mu \mathrm{m}$ filter and afterwards the remaining AC washed with $100 \mathrm{~mL}$ of clean water. The remaining concentration of RAMEB in the water was measured with HPLC-ELSD.

\subsection{Column experiments}

In the final experiment, $500 \mathrm{~g}$ (wet weight) of sandy soil contaminated with diesel (4220 mg MO/kg DW, 79.9\% DW and 1.7\% organic matter) was packed in eight different glass columns $(5 \mathrm{~cm}$ i.d.) and from the bottom filled with 1.5 pore volumes of tap water. The soil was compressed using a disk of the same diameter until a height of 
$20 \mathrm{~cm}$ was obtained for all the columns. The density of the soil in the column was $1.23 \mathrm{~g} / \mathrm{cm}^{3}$.

After $24 \mathrm{~h}$ of conditioning, the water of six columns was replaced with $20 \mathrm{~g} / \mathrm{L} \mathrm{CD}$ solution (w/v) for six columns. The remaining two columns were flushed with tap water without cyclodextrin as a control. The water of three of the columns flushed with cyclodextrin solution was led to an AC filter. The filter consisted of a glass column (diameter $2 \mathrm{~cm}$ and height $25 \mathrm{~cm}$ ) completely filled with granular AC type AC-C. An overview of the set-up of the column experiment is given in Table 1. The columns were flushed for 8 weeks using a peristaltic pump set at a flow rate of $10 \mathrm{~mL} / \mathrm{h}$. This corresponds to a pore water velocity of $2.5 \mathrm{~cm} / \mathrm{h}$. The flow rate was maintained for $8.5 \mathrm{~h}$, after which the flow was ceased for a period of $3.5 \mathrm{~h}$. By repeating this cycle, the columns were flushed 16 times with either tap water or a CD solution each week. Each week, the cumulated concentration of $\mathrm{MO}$ and $\mathrm{CD}$ in the collected effluent water was determined.

\subsection{Analyses}

HPLC-ELSD equipped with an RP-C18 column (5 $\mu \mathrm{m}, 125 \times 4 \mathrm{~mm})$ was used for the analysis of RAMEB in the water. An isocratic mobile phase of $75 \%$ acetonitrile and $25 \%$ of water was used at a flow of $1.0 \mathrm{~mL} / \mathrm{min}$. The amount of cyclodextrin was detected with ELSD set at $40{ }^{\circ} \mathrm{C}$ and 3.0 bar.

The amount of mineral oil in $1 \mathrm{~L}$ of the flushed water was measured with GC-FID after liquid-liquid extraction with hexane. The extract was concentrated by evaporation to $1 \mathrm{~mL}$. A mixture of C10 and C40 was added to the extract to define the boundaries of the mineral oil peaks in the chromatogram. Mineral oil was separated using a DB-5 ms column ( $30 \mathrm{~m} \times 0.25 \mathrm{~mm}, 0.25 \mu \mathrm{m})$. Volumes of $1 \mu \mathrm{L}$ were injected on the column with helium as carrier gas. The initial temperature of $50{ }^{\circ} \mathrm{C}$ increased after $3 \mathrm{~min}$ with $25{ }^{\circ} \mathrm{C} / \mathrm{min}$ until $315{ }^{\circ} \mathrm{C}$ was obtained. After $20 \mathrm{~min}$, the temperature decreased again until $50{ }^{\circ} \mathrm{C}$. The area sum between $\mathrm{C} 10$ and $\mathrm{C} 40$ was used to determine the concentration of mineral oil in the sample. The concentration of mineral oil was calculated based on a calibration curve made with a standard mineral oil solution from the Dutch institute of public health and the environment (RIVM).

\section{Results}

\subsection{Adsorption of cyclodextrin to activated carbon}

Fig. 2 shows that cyclodextrin is indeed sorbed to the surface of some of the AC and that a significant amount of cyclodextrin is removed from the solution. The effects are visible at concentrations higher than $2 \mathrm{~g} / \mathrm{L}$ of AC. For AC-A and AC-D only 12 and $78 \%$ of the initial amount of RAMEB remains in the solution when $10 \mathrm{~g} / \mathrm{L}$ of $\mathrm{AC}$ is added to the solution. On the other hand, AC-C only removes $4 \%$ of RAMEB from the solution, while with AC-B a $100 \%$ of the initial amount of RAMEB is still found in the solution. It seems that $A C-B$ and $A C-C$, originating from coco shells are the most appropriate to use when we aim to reuse the RAMEB solution.

Table 1

Set-up of the column experiment.

\begin{tabular}{lll}
\hline Column & $\begin{array}{l}\text { Concentration of cyclodextrin } \\
\text { in tap water }(\mathrm{g} / \mathrm{L})\end{array}$ & AC filter? \\
\hline $0 \mathrm{~g} / \mathrm{L}(1)$ & 0 & No \\
$0 \mathrm{~g} / \mathrm{L}(2)$ & 0 & No \\
$20 \mathrm{~g} / \mathrm{L}(1)$ & 20 & No \\
$20 \mathrm{~g} / \mathrm{L}(2)$ & 20 & No \\
$20 \mathrm{~g} / \mathrm{L}(3)$ & 20 & No \\
$20 \mathrm{~g} / \mathrm{L}+\mathrm{AC}(1)$ & 20 & Yes \\
$20 \mathrm{~g} / \mathrm{L}+\mathrm{AC}(2)$ & 20 & Yes \\
$20 \mathrm{~g} / \mathrm{L}+\mathrm{AC}(3)$ & 20 & Yes \\
\hline
\end{tabular}

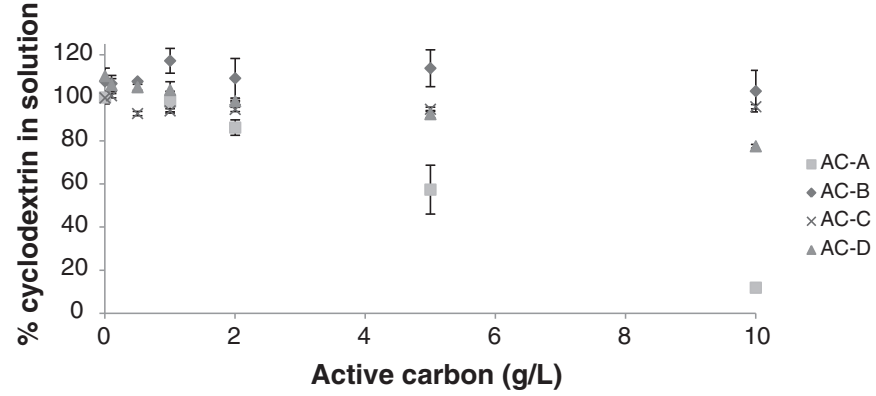

Fig. 2. Adsorption of cyclodextrin to four different types of activated carbon. Average values of duplicates with the respective standard deviation are shown.

Since it is more likely that concentrations higher than $10 \mathrm{~g} / \mathrm{L}$ of RAMEB are necessary to enhance the pump and treat process, the loss of RAMEB by AC when higher concentrations of RAMEB are used is determined. The results for AC-B in Fig. 3 indicate that with increasing concentration of RAMEB, more RAMEB is sorbed to the AC. Probably only a small fraction of RAMEB binds to AC-B, but these losses become significant at higher concentrations of RAMEB in the water. On the other hand $\mathrm{AC}-\mathrm{C}$ does not show any sorption capacity for RAMEB. Therefore, AC-C seems to be the most suitable to recover RAMEB from the flushing solution and was therefore selected for the column experiment.

\subsection{Column experiment}

A column experiment was performed to simulate soil flushing conditions and to produce realistic soil washing water containing high concentrations of mineral oil and dissolved organic matter. Both compounds might either enhance the adsorption of RAMEB to the AC or deteriorate the adsorption capacity of AC for mineral oil to treat the contaminated water. Both effects are highly undetrimental for the soil treatment practice.

Flushing the columns with $20 \mathrm{~g} / \mathrm{L}$ of RAMEB clearly enhanced the amount of MO rinsed from the soil. Table 2 shows that after 8 weeks of flushing (equal with $7.7 \mathrm{~L}$ of tap water) only $0.03 \%$ of the initial amount of MO in the soil was found in the effluent. This corresponds to an average $\mathrm{MO}$ concentration of $0.10 \mathrm{mg} / \mathrm{L}$ of $\mathrm{MO}$ in the washing water. In contrast, the effluent of the columns flushed with the cyclodextrin solution contained an average of $11.4 \%$ or $191 \mathrm{mg}$ of MO, which corresponds to an average MO concentration of $27 \mathrm{mg} / \mathrm{L}$. This means that between 280 and 380 times more MO was removed with the cyclodextrin solution or that $1.4 \mathrm{mg}$ of MO was removed with each $g$ of RAMEB.

Interestingly, during the whole experimental period a $100 \%$ of the cyclodextrin concentration was found in the water collected from the

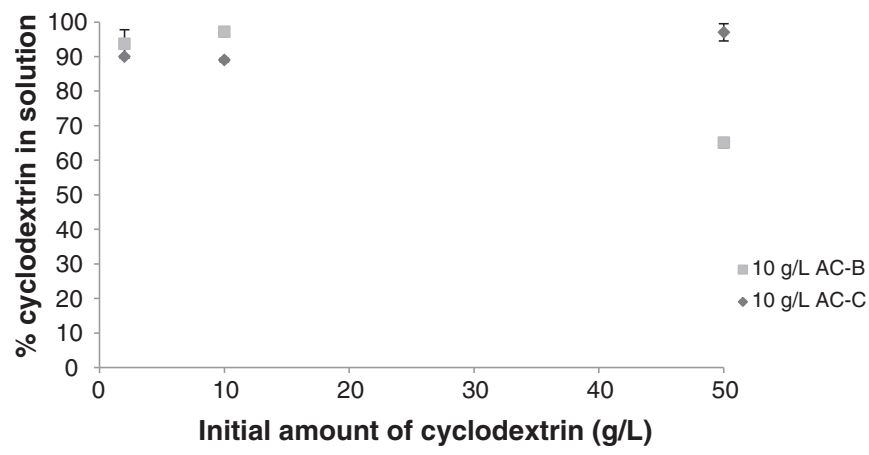

Fig. 3. Effect of cyclodextrin concentration on the adsorption to two different types of activated carbon. Average values of duplicates with the respective standard deviation are shown. 
Table 2

Total amount of mineral oil flushed from the columns with tap water with or without $20 \mathrm{~g} / \mathrm{L}$ of cyclodextrin after 56 days.

\begin{tabular}{llc}
\hline & $0 \mathrm{~g} / \mathrm{L}$ & $20 \mathrm{~g} / \mathrm{L}$ \\
\hline Total volume (L) & $7.7( \pm 0.3)$ & $7.1( \pm 0.5)$ \\
Total MO (mg) & $0.79( \pm 0.04)$ & $191( \pm 29)$ \\
\% MO flushed & $0.03( \pm 0.00)$ & $11.4 \pm( \pm 1.14)$ \\
Average MO (mg/L) & $0.10( \pm 0.00)$ & $27.09( \pm 2.7)$ \\
Total amount of CD (g) & 0 & $132( \pm 6.6)$ \\
Removal efficiency (mg MO/g CD) & N/A & $1.4( \pm 0.14)$ \\
\hline
\end{tabular}

N/A: not applicable.

Table 3

The amount of cyclodextrin found in the effluent of the different types of columns.

\begin{tabular}{ll}
\hline Column & $\%$ CD in effluent \\
\hline $0 \mathrm{~g} / \mathrm{L}(1)$ & $<\mathrm{LOD}$ \\
$0 \mathrm{~g} / \mathrm{L}(2)$ & $<\mathrm{LOD}$ \\
$20 \mathrm{~g} / \mathrm{L}(1)$ & 99 \\
$20 \mathrm{~g} / \mathrm{L}(2)$ & 100 \\
$20 \mathrm{~g} / \mathrm{L}(3)$ & 101 \\
$20 \mathrm{~g} / \mathrm{L}+\mathrm{AC}(1)$ & 99 \\
$20 \mathrm{~g} / \mathrm{L}+\mathrm{AC}(2)$ & 100 \\
$20 \mathrm{~g} / \mathrm{L}+\mathrm{AC}(3)$ & 99 \\
\hline
\end{tabular}

columns without AC-filter and $100 \%$ in the effluent of the columns with AC-filter (Table 3). So no significant losses of RAMEB to the soil or to the AC filter were observed.

Finally, we looked at the cleaning efficiency of the AC filter and whether this is affected by the inclusion complex formed with $C D$ and the presence of dissolved organic matter. Table 4 gives an overview of the amount of MO found in the effluent of the columns with and without the AC filter. It is shown that more than $90 \%$ of the MO flushed from the columns was retained by the active carbon filter. During the first 3 weeks a significant higher amount of MO was found after filtering the contaminated water. This was due to a leak in the filters which caused only a part of the effluent water running through the filter. This problem was solved during the fourth week, which is shown by the higher removal efficiency ( $>90 \%$ ) of the AC filter.

Based on these results it appears that the inclusion complex easily dissociates and that the $\mathrm{MO}$ is retained by the AC. A similar observation was made by Gao and Blanford (2012) who found no indication that the distribution of trichloroethene within the dissolved and granular AC phase is affected by the presence of hydroxypropyl- $\beta$-cyclodextrin. However, still a significant amount of MO remains in the water. This might be due to a small part of MO that remains associated with the RAMEB molecules. Indeed, $1.4 \mathrm{mg} \mathrm{MO}$ is dissolved for each $\mathrm{g}$ of RAMEB. On the other hand, it might be simply due to (i) the very high concentrations of $\mathrm{MO}$ in the effluent, (ii) a short cut flow in the adsorption column or (iii) the low affinity of some diesel compounds for AC which therefore remain in the water.

When the efficiency of the AC filter to remove the different fractions of diesel from the flushing water is examined in more detail, it shows that the composition of the mineral oil after the AC filter changed due to different removal \% for the different oil fractions. Table 5 shows the relative amount of the different mineral oil fractions removed from

\section{Table 5}

Initial amount of mineral oil in the soil, average amount of mineral oil removed by the cyclodextrin-containing flushing water and average removal percentage of the active carbon filter for the different fractions of diesel.

\begin{tabular}{lrccl}
\hline $\begin{array}{l}\text { Amount of } \\
\text { mineral oil: }\end{array}$ & Initial $(\mathrm{mg} / \mathrm{kg} \mathrm{dw})$ & $\begin{array}{l}\text { MO flushed } \\
(\mathrm{mg} / \mathrm{kg} \mathrm{dw})\end{array}$ & MO flushed (\%) & $\begin{array}{l}\text { Removed with } \\
\mathrm{AC}^{\mathrm{a}}(\%)\end{array}$ \\
\hline C10-C40 & 4220 & 481 & 11.4 & 92.2 \\
C10-C12 & 281 & 55 & 19.6 & 99.6 \\
C12-C20 & 3060 & 313 & 10.2 & 93.1 \\
C20-C30 & 812 & 38 & 4.8 & 78.2 \\
C30-C40 & 68 & 6.6 & 9.7 & 94.1 \\
\hline
\end{tabular}

a Calculated based on the results of Day 28-56, when there was no leak in the AC filter.

the soil by cyclodextrin-flushing and from the flushing water by AC filtration. The active carbon filter seems to be less efficient in removing the C20-C30 fraction (78.2\%), indicating a lower affinity of this fraction for the AC compared to the other mineral oil fractions that are relatively better removed (93.1-99.6\%). Furthermore, the contribution of the C20-C30 fraction to the remaining amount of mineral oil in the water after AC filtration is only limited $(+-30 \%)$. It seems therefore that besides the low affinity of the $\mathrm{AC}$ for the $\mathrm{C} 20-\mathrm{C} 30$ fraction, the elevated concentrations in the flushing water are mainly responsible for the remaining mineral oil concentration in the filtered water. The contribution of a short cut flow seems therefore less important. It should be noted that the initial amount of $\mathrm{C} 10-\mathrm{C} 12$ and $\mathrm{C} 30-\mathrm{C} 40$ in the soil is relatively low which makes the calculated removal \% less reliable.

Installing a double AC filter will probably remove the remaining amount of MO. It seems that with time the removal efficiency of AC decreases, however since the difference is not significant it is not clear whether the AC filter is starting to lose its efficiency. It is possible that with the cyclodextrin solution not only a significant amount of MO, but also an increasing amount of dissolved organic matter is flushed through the filter which might accelerate the saturation rate. Additional measurements confirmed that the presence of CD (50 g/L) triples the absorbance at $254 \mathrm{~nm}$ in the soil water, which indicates that the amount of dissolved organic matter increases. However, a long-term column experiment or pilot-test is necessary to confirm whether this accelerates the saturation of AC.

\section{Conclusions and recommendations}

In situ soil flushing with a cyclodextrin solution significantly accelerates the clean-up of soils contaminated with mineral oil, but the high costs of cyclodextrin discourage the applicability in the field. A reuse of the cyclodextrin molecules would significantly reduce the overall costs of the process. This study proposes to use AC filters to disintegrate the cyclodextrin-mineral oil complex in order to remove the mineral oil from the water and reuse the cyclodextrin solution. The results indicate that $100 \%$ of the RAMEB solution can be recovered from contaminated washing water by using an AC filter made of coco shells. Although the AC filter removes more than $90 \%$ of the mineral oil from the flushing water, a significant amount of mineral oil remains in the water. However, whether this is caused by the cyclodextrin-mineral oil complex which does not dissociates completely or the high concentrations of mineral oil in the water combined with the lower affinity of AC for some mineral oil fractions is not clear. Overall, it seems that RAMEB does not jeopardize

Table 4

The amount of mineral oil in the effluent during eight weeks of flushing with $20 \mathrm{~g} / \mathrm{L}$ of cyclodextrin solution.

\begin{tabular}{|c|c|c|c|c|c|c|c|c|}
\hline \multicolumn{2}{|c|}{ Amount of MO in effluent } & \multirow{2}{*}{$\begin{array}{l}\text { Day } 7 \\
50.5\end{array}$} & \multirow{2}{*}{$\begin{array}{l}\text { Day } 14 \\
43.4\end{array}$} & \multirow{2}{*}{$\begin{array}{l}\text { Day } 21 \\
19.0\end{array}$} & \multirow{2}{*}{$\frac{\text { Day } 28}{35.7}$} & \multirow{2}{*}{$\frac{\text { Day } 35}{26.0}$} & \multirow{2}{*}{$\frac{\text { Day } 49}{15.6}$} & \multirow{2}{*}{$\begin{array}{l}\text { Day } 56 \\
16.7\end{array}$} \\
\hline Without AC filter & Average (mg/L) & & & & & & & \\
\hline & St. $\operatorname{dev}(\mathrm{mg} / \mathrm{L})$ & 4.1 & 6.8 & 3.4 & 6.1 & 3.3 & 2.4 & 0.6 \\
\hline \multirow[t]{2}{*}{ With AC filter } & Average $(\mathrm{mg} / \mathrm{L})$ & 6.8 & 10.3 & 4.0 & 2.1 & 1.9 & 1.2 & 1.5 \\
\hline & St. $\operatorname{dev}(\mathrm{mg} / \mathrm{L})$ & 1.1 & 1.0 & 0.8 & 0.6 & 0.5 & 0.4 & 0.3 \\
\hline \multicolumn{2}{|c|}{ MO removed with AC (\%) } & 86.6 & 76.2 & 78.9 & 94.0 & 92.7 & 91.8 & 90.7 \\
\hline
\end{tabular}


the high purification efficiency of AC to remove organic pollutants from the washing water.

The results of this study are very promising to make this technique economically feasible and to integrate it in common soil remediation methods. However, additional field trials are recommended to test how much of $\mathrm{CD}$ can be recovered from the soil taken into account the heterogeneity of the subsoil and secondly to determine how fast the AC filter becomes saturated due to the significant higher concentrations of organic contaminants and dissolved organic carbon in the washing water. In addition, special attention should be given to the design of the soil flushing installation to avoid that too much of groundwater of the surrounding environment is pumped into the circulation system, which dilutes the inserted CD solution. Results from other flushing experiments (own data, unpublished) showed that high concentrations of $\mathrm{CD}$ solutions are required to achieve a high removal efficiency within a reasonable time. In case of dilution, it will be necessary to concentrate the pumped water to increase the $\mathrm{CD}$ concentration to a suitable level after cleaning the washing water with $\mathrm{AC}$ or adding $\mathrm{CD}$ molecules, which will only increase the operating costs of the technique.

\section{References}

Balogh K, Szaniszlo N, H-Otta K, Fenyvesi E. Can cyclodextrins really improve the selectivity of extraction of BTEX compounds? J Incl Phenom Macro 2007:57:457-62.

Berselli S, Benitez E, Stefano FI, Zannoni D, Medici A, Marchetti L, Fava F. Development and assessment of an innovative soil-washing process based on the use of cholic acid-derivatives as pollutant-mobilizing agents. Biotechnol Bioeng 2006;93:761-70.

Blanford WJ, Barackman ML, Boing TB, Klingel EJ, Johnson GR, Brusseau ML. Cyclodextrinenhanced vertical flushing of a trichloroethene contaminated aquifer. Ground Water Monit Rem 2001;21:58-66.

Boving T, Wang X, Brusseau ML. Use of cyclodextrins for the remediation of solvent contaminated porous media. IAHS-AISH P 1998;250:437-40.

Brusseau ML, Wang X, Hu Q. Enhanced transport of low-polarity organic compounds through soil by Cyclodextrin. Environ Sci Technol 1994;28:952-6.

Davis ME, Brewster ME. Cyclodextrin-based pharmaceutics: past, present and future. Nat Rev Drug Discov 2004;3:1023-35.

Fava F, Ciccotosto V. Effects of randomly methylated- $\beta$-cyclodextrins (RAMEB) on the bioavailability and aerobic biodegradation of polychlorinated biphenyls in three pristine soils spiked with a transformer oil. Appl Microbiol Biotechnol 2002;58:393-9.

Fenyvesi É, Gruiz K, Verstichel S, De Wilde B, Leitgib L, Csabai K, Szaniszlo N. Biodegradation of cyclodextrins in soil. Chemosphere 2005;60:1001-8.
Fenyvesi É, Molnár M, Leitgib L, Gruiz K. Cyclodextrin-enhanced soil-remediation technologies. Land Contam Reclam 2009;17:3-4.

Fenyvesi É, Balogh K, Oláh E, Bátai B, Varga E, Molnár M, Gruiz K. Cyclodextrins for remediation of soils contaminated with chlorinated organics. J Incl Phenom Macro 2010:1-7.

Gan S, Lau E, Ng H. Remediation of soils contaminated with polycyclic aromatic hydrocarbons (PAHs). J Hazard Mater 2009;172:532-49.

Gao H, Blanford WJ. Partitioning behavior of trichloroethylene in cyclodextrin-watergranular-activated carbon systems. Environ Eng Sci 2012;29:533-9.

Kania N, Rio S, Monflier E, Ponchel A. Cyclodextrins adsorbed onto activated carbons: preparation, characterization, and effect on the dispersibility of the particles in water. J Colloid Interface Sci 2012;371:89-100.

Kosaric N. Biosurfactants for soil bioremediation. Food Technol Biotechnol 2001;39:295-304.

Leitgib L, Gruiz K, Fenyvesi E, Balogh G, Muranyi A. Development of an innovative soil remediation: "cyclodextrin-enhanced combined technology". Sci Total Environ 2008;392:12-21.

McCray JE, Brusseau ML. Cyclodextrin-enhanced in situ flushing of multiple-component immiscible organic liquid contamination at the field scale: mass removal effectiveness. Environ Sci Technol 1998;32:1285-93.

McCray J, Boving T, Brusseau ML. Cyclodextrin-enhanced solubilization of organic contaminants with implications for aquifer remediation. Winter 2000:94-103.

Molnár M, Fenyvesi É, Gruiz K, Leitgib L, Balogh G, Murányi A, et al. Effects of RAMEB on bioremediation of different soils contaminated with hydrocarbons. J Incl Phenom Macrocycl Chem 2002;44:447-52.

Molnár M, Leitgib L, Gruiz K, Fenyvesi É, Szanisló N, Szejtli J, et al. Enhanced biodegradation of transformer oil in soils with cyclodextrin - from the laboratory to the field. Biodegradation 2005;16:159-68.

Morillo E, Perez-Martinez JI, Gines JM. Leaching of 2,4-D from a soil in the presence of beta-cyclodextrin: laboratory columns experiments. Chemosphere 2001;44:1065-9.

Morley MC, Speitel Jr GE, Fatemi M. Enhanced desorption of RDX from granular activated carbon. Water Environ Res 2006;78:312-20.

Svab M, Kubal M, Müllerova M, Raschman R. Soil flushing by surfactant solution: pilot-scale demonstration of complete technology. J Hazard Mater 2009;163:410-7.

Tick GR, Lourenso F, Wood AL, Brusseau ML. Pilot-scale demonstration of cyclodextrin as a solubility enhancement agent for remediation of a tetrachloroethene contaminated aquifer. Environ Sci Technol 2003;37:5829-34.

Viglianti C, Hanna K, de Brauer C, Germain P. Removal of polycyclic aromatic hydrocarbons from aged-contaminated soil using CD: experimental study. Environ Pollut 2006;140:427-35.

Wang JM, Maier RM, Brusseau ML. Influence of hydroxypropyl-[beta]-cyclodextrin (HPCD) on the bioavailability and biodegradation of pyrene. Chemosphere 2005;60:725-8

Wong F, Bidleman TF. Hydroxypropyl- $\beta$-cyclodextrin as non-exhaustive extractant for organochlorine pesticides and polychlorinated biphenyls in muck soil. Environ Pollut 2010;158:1303-10

Zeng QR, Tang HX, Liao BH, Zhong TF, Tang C. Solubilization and desorption of methylparathion from porous media: a comparison of hydroxypropyl-beta-cyclodextrin and two nonionic surfactants. Water Res 2006;40:1351-8.

Zhou W, Zhu L. Enhanced soil flushing of phenanthrene by anionic/nonionic mixed surfactant. Water Res 2008;42:101-8. 